\title{
DIREITO AO ESQUECIMENTO E SUA FUNDAMENTAÇÃO PRIORITÁRIA NO LIVRE DESENVOLVIMENTO DA IDENTIDADE PESSOAL
}

\author{
THE RIGHT TO BE FORGOTTEN AND ITS FOUNDATION BASED \\ ON THE FREE DEVELOPMENT OF PERSONAL IDENTITY
}

\author{
Arthur Maria Ferreira Neto
}

\section{RESUMO}

O propósito central do presente artigo, é analisar criticamente a denominação que veio a ser consolidada (até o presente momento) pela doutrina e pela jurisprudência para se referir ao catálogo de pretensões jurídicas que são amparadas pelo rótulo "direito ao esquecimento". Pretende-se averiguar, por meio de estudo comparativo, se tal expressão se mostra, de fato, adequada e coerente com os elementos jurídicos essenciais que efetivamente visam a ser protegidos e resguardados por meio desse novo direito fundamental. Em segundo lugar, busca-se identificar, neste texto, o fundamento jurídico principal do "direito ao esquecimento", de modo a demonstrar, ao final, que, não obstante mantenha relação paralela com a proteção à privacidade do indivíduo, tal novel pretensão jurídica possui uma relação direta e mais demarcada com o resguardo de direitos de personalidade, mais especificamente a autodeterminação da identidade informacional do particular. Adotou-se, neste estudo, como metodologia, a pesquisa bibliográfica e o estudo jurisprudencial em direito comparado envolvendo o "direito ao esquecimento".

Palavras-chave: Direitos de personalidade. Internet. Proteção à privacidade. Direito ao esquecimento. Livre desenvolvimento de identidade pessoal nas mídias sociais. 


\section{ABSTRACT}

The main purpose of this paper is, first, to analyze critically the concept which was gradually constructed by legal theory and by Court rulings to refer to the catalog of legal claims that are covered by the label "Right to be forgotten". This article intends to, by comparative study, verify if such an expression is in fact appropriate and consistent with the essential legal elements that effectively seek to be protected and safeguarded by means of this new fundamental right. Secondly, this text seeks to identify the legal basis of the "right to be forgotten", in order to demonstrate that its ultimate justification is not properly based on the protection of privacy rights of the individual but actually involves primarily a way to safeguard rights of personality, more specifically a self-determination right to informational identity. In this paper, the methodology adopted was of bibliographical research and the revision of foreign court precedents for the comparative study of the "right to be forgotten".

Keywords: Personality rights. Privacy protection. Right to be forgotten. Free development of personal identity in social media.

\section{INTRODUÇÃO}

Na história, a extensão da memória individual quase sempre esteve exclusivamente contida nos corpos dos indivíduos ou materializada em alguns objetos físicos que esses carregariam consigo. Essa característica, no passado, trazia uma clara vantagem, qual seja, permitia um controle direto sobre o que seria conservado como digno de memorização, bem como dava uma relativa garantia de que terceiros não poderiam, indevidamente, acessar nem transmitir tais informações sem nosso consentimento ou ciência. Em contrapartida, nesse contexto pretérito, a memória deixava (e, no tocante à capacidade do cérebro humano como tal, ainda deixa) a desejar, pois não apenas manifestava um volume de armazenagem limitado, como também atribuía às informações guardadas um traço de precariedade e fragilidade, o que invariavelmente conduzia à sua gradual depreciação, até o ponto do esquecimento completo de muitos fatos e experiências (GHEZZI; PEREIRA; VESNIC-ALUJEVIC, 2014, p. 10). 
Em contrapartida, na atualidade, a forma como os indivíduos se relacionam com a sua memória foi completamente modificada, seja no que tange ao volume do conteúdo informacional preservado, seja no que se refere à segurança e persistência com que esse pode ser armazenado. Isso se dá em razão do desenvolvimento, neste século, da chamada "memória digital", forjada graças à natureza integralmente pervasiva da rede mundial de computadores (PENA, 2014, p. 19-20). Aliás, essa mudança se deu de modo gradual com o passar dos anos, provocada por inúmeras revoluções tecnológicas a que se submeteu (e vem se submetendo) a Internet. Com efeito, tornou-se comum separar cronologicamente a evolução da Rede Mundial de Computadores em três (ou, para alguns, quatro) etapas distintas, tendo em vista a forma como veio ela a ser prioritariamente recebida pelos seus usuários.

Assim, em uma primeira etapa, também chamada de Web 1.0 (a expressão é de Tim O’Reilly), a Internet era tomada, exclusivamente, como um instrumento de busca e obtenção de informações armazenadas em suas redes de dados. A partir de 2004, passou-se a caracterizar a Internet pelo termo Web 2.0, o que é representado pela ideia de que a rede mundial de computadores permitiu aos usuários não mais apenas o consumo de informações, mas também a participação na elaboração, construção e gestão do conhecimento disponível na Internet. Passamos, assim, a ter a chamada web social ou web colaborativa, a qual originou sítios como Youtube, Wikipédia, dentre outros. Em terceiro lugar, surge a Web 3.0, também denominada de semântica, em que a interação com a realidade se tornou mais precisa, sensível e concreta, graças a uma forma mais aprimorada de definição, ordenação e hierarquização das informações disponíveis. A Web 3.0 permitiu a construção de conhecimento direcionado ao contexto de cada particular, tendo em vista suas características e preferências. Por fim, identifica-se o surgimento e o processo de maturação (ainda em curso) de uma Web 4.0 ou Web predicativa, a qual, com base em informações disponíveis em seu sistema de dados, consegue antecipar as necessidades dos seus usuários, de modo a atuar quase como um centro autônomo de tomada de decisões do particular, como se fosse uma espécie de cérebro paralelo. 
Além disso, a Internet, como bem sabido, representa não apenas uma mudança tecnológica, mas envolve também uma alteração cultural na forma como os indivíduos interagem entre si e com a realidade - e, quanto maior a interação social na troca de dados, maior a potencialidade para conflitos. Desse modo, a chamada memória digital assume uma dimensão híbrida, na medida em que, além de estar contida em estruturas externas ao indivíduo, e ser formada por ferramentas materiais (provedores) e imateriais (armazenamento de dados na nuvem), pode ser formatada não apenas pelo destinatário da memória, mas também por terceiros que participam de um ambiente coletivo em que tais informações são produzidas e compartilhadas. Isso culmina na potencial interferência desses terceiros na esfera de interesses daqueles cujos dados pessoais acabam sendo acessados de modo comum.

Essa nova forma de interação com as próprias memórias permite superar as dificuldades antes apontadas, garantindo a possibilidade de lembrança quase ilimitada e, com relativa segurança, a preservação duradora desses dados, criando, assim, o que alguns chamam de efeito eternidade da informação (GHEZZI; PEREIRA; VESNIC-ALUJEVIC, 2014, p. 11). Porém, a consequência desta possibilidade, de os dados pessoais serem guardados eternamente, é o surgimento do risco de não ser mais possível esquecer o passado, o qual poderá ser lembrado (e livremente interpretado ${ }^{1}$ ) por todos, a qualquer momento, com grande facilidade de acesso público e enorme potencial de transmissão global. Com isso, o lembrar passa a ser a regra e a possibilidade de esquecimento - com o benéfico efeito de superar o passado, perdoar erros cometidos e permitir o aprimoramento pessoal - passa a ser exceção, submetendo os indivíduos ao risco de ficarem aprisionados em uma memória perfeita, que não permite que nada seja obliterado. Ocorre que, com a revolução digital e a ampliação do acesso a novas tecnologias, passa-se a cultivar uma postura de revelação pública, quase ilimitada, de aspectos da vida privada (caracterizada como uma tendência ao novo exibicionismo do Século XXI) - (CHADWICK, LEVITT, SCHICKLE, 2014, p. 13), aspectos esses que passam a ser registrados automaticamente na Internet e armazenados para sempre nos seus sistemas informatizados. Com isso, nesse contexto, a regra default deixa de ser a privacidade no manejo de dados pessoais, 
e passa a ser a ampla e irrestrita publicidade. Alguns autores chegam a denominar esse padrão de conduta como sendo privacy by default (PENA, 2014, p. 23). Consequência disso é a mudança de paradigma, em que a lembrança passa a ser a regra geral e o esquecimento a exceção, criando-se, assim, a noção da referida memória perfeita, que impede a sociedade humana de esquecer qualquer elemento do seu passado (MAYER-SCHONBERGER, 2009, p. 92).

Portanto, segundo Hoskins (2014, p. 51), com esse novo paradigma digital, conseguimos superar, pela primeira vez na história da humanidade, a chamada cultura da escassez informacional, em que o acesso a informações sofria limitadores, no que se refere ao seu conteúdo, à extensão do seu acesso, e às tecnologias de transmissão e armazenamento. Diante disso, vivemos hoje o fenômeno inédito do paradigma da pós-escassez, em que a sociedade está lutando para conviver com uma nova escala de informações sobre o seu passado e sobre o seu presente, resultando no desequilíbrio na forma como são criadas, modificadas e transmitidas as memórias (individuais e coletivas).

Esse cenário de pós-escassez informacional, mesmo que faça surgir expressivas vantagens, acaba criando, como efeito colateral, uma série de novos desafios jurídicos e dilemas éticos, os quais precisam ser enfrentados com clareza e transparência, tanto pelo Direito quanto por outras instituições sociais.

Dentre esses novos desafios e paradoxos, surge neste século a configuração de um possível novo direito fundamental, este que acabou assumindo a nomenclatura de "direito ao esquecimento", estruturado com o propósito de regular e proteger precisamente as relações sociais surgidas dentro do contexto de ampla troca de informações e de armazenamento quase irrestrito de dados pessoais.

Esse, portanto, é o propósito central do presente artigo, qual seja, em um primeiro momento, analisar criticamente a denominação que veio a ser consolidada (até o presente momento) pela doutrina e pela jurisprudência para se referir ao catálogo de pretensões jurídicas que são amparadas pelo rótulo "direito ao esquecimento".

A metodologia adotada no presente artigo é prioritariamente analítico-conceitual, envolvendo a revisão de bibliografia nacional e 
estrangeira, de modo a promover estudo comparativo e crítico do termo "direito ao esquecimento", com o intuito de verificar se tal expressão se mostra, de fato, adequada e coerente aos elementos jurídicos essenciais que efetivamente visam a ser protegidos e resguardados por meio desse novo direito fundamental. Em segundo lugar, busca-se identificar, neste texto, o fundamento jurídico principal do direito ao esquecimento, de modo a verificar se a sua justificação última se escora na proteção à privacidade do indivíduo, ou se envolve uma forma de resguardar direitos de personalidade, mais especificamente a autodeterminação da identidade informacional do particular.

Por fim, cabe ressaltar que o presente artigo pode ser compreendido como uma complementação (e não uma revisão) de texto anteriormente publicado por este autor sobre este mesmo tema (FERREIRA NETO, 2016). Naquela ocasião, porém, o objetivo central foi o de resgatar os fundamentos ontológicos e filosóficos do "direito ao esquecimento" (tempo e memória), propondo, por meio da análise de precedentes de tribunais, tanto em plano internacional, quanto nacional (aqui especificamente o Superior Tribunal de Justiça), a observância de quatro critérios aplicativos que poderiam ser observados na concretização do direito ao esquecimento em casos futuros a serem apreciados pelo Poder Judiciário ("Fato prejudicial, vexatório ou desabonador; Transcurso razoável de tempo ou não contemporaneidade; Ausência de historicidade; Esgotamento da relevância informativa do evento ou o atingimento da recomposição penal pela reabilitação e perdão"). Por essa razão, não se pretende, neste estudo, retomar a descrição de todos os casos e precedentes analisados no artigo anterior deste autor. Aqui, em verdade, pretende-se promover um aprofundamento na análise conceitual e da fundamentação propriamente jurídica do chamado "direito ao esquecimento". 


\section{FATORES TECNOLÓGICOS, SOCIAIS E CULTURAIS QUE FORMAM O “DIREITO AO ESQUECIMENTO”}

Inúmeros e complexos são os fatores que culminam na formatação do chamado direito ao esquecimento no Século XXI. Senão, vejamos.

Em primeiro lugar, conforme adiantado na introdução do presente artigo, o ambiente de hiperconectividade, antes destacado, provoca uma mudança paradigmática no que se refere à forma como lidamos com a lembrança e com o esquecimento. Isso porque, de modo inédito na história da humanidade, torna-se possível falar - em termos tecnológicos - em uma memória perfeita, a qual, segundo Mayer-schonberger (2009), deve-se a quatro fatores que marcam o surgimento da sociedade da hiperinformação, quais sejam:

(i) a digitalização: a mudança de registros em formato analógico ${ }^{2}$ para registros digitais permitiu que a informação armazenada tivesse aumento na sua fidelidade e precisão relativamente à sua fonte original;

(ii) a armazenagem barata de informação: a facilidade no processo de digitalização de dados, com grande fidelidade da informação reproduzida, torna a sua armazenagem extremamente econômica, o que, inclusive, torna a atividade de esquecer mais dispendiosa do que a de lembrar ${ }^{3}$;

(iii) a recuperação rápida de dados: diferentemente de bibliotecas, em que a retomada de alguma informação relevante exige longas horas de pesquisa, o formato digital de armazenagem de dados permite uma recuperação quase imediata daquilo que deseja ser lembrado, o que inclusive acaba atribuindo mais valor ao conteúdo armazenado (MAYERSCHONBERGER, 2009, p. 73);

(iv) e o alcance global na transmissão de informação, o que culmina, de um lado, na possibilidade de compartilhar conhecimento com pessoas que estejam nos locais mais remotos do mundo, mas, de outro, faz com que um dado, assim que inserido na rede mundial de computadores, passe a ser irrestritamente público e compartilhável, sem mais qualquer chance de controle por parte daquele que veio a dispor dessa parcela de informação (MAYER-SCHONBERGER, 2009, p. 91).

E isso, por sua vez, acaba criando uma contradição no que se refere à mudança no status que atribuímos à memória (HOSKINS, 2014, p. 53). 
Isso porque, de um lado, passa-se a ter um contato imediato e perene com o passado, o que atribui uma nova sensação de os indivíduos serem capazes de ver, organizar, armazenar e até deletar as suas memórias. No entanto, essa mesma sensação de autocontrole acaba tornando-os vulneráveis a uma memória sempre acessível e resgatável, de modo a tornar o indivíduo refém do seu passado. Isso acaba criando o fenômeno da emergência de fatos passados (HOSKINS, 2014, p. 54), segundo o qual, diante do volume incontrolável de registros digitais de todos os aspectos de nossa vida diária, determinado evento que afetou a vida de alguém pode vir à tona repentinamente, fazendo emergir, mais uma vez, o passado no presente. Este fenômeno acaba impedindo que o tempo exerça a sua função natural de corroer ocorrências pretéritas e depreciar o valor original de eventos do passado, o que, em regra, sempre teve uma importante função estabilizadora, no sentido de garantir aos indivíduos segurança e certeza de que o presente iria, gradualmente, se sobrepondo ao passado. Assim, na sociedade da hiperconexão, isso não mais ocorre, uma vez que a íntegra do passado é transformada em um presente digitalizado, pronto para nos assombrar, mas agora descontextualizado, confuso e eternamente indefinido.

Em segundo lugar, essa perenidade da memória digital e a perda na capacidade de esquecimento ${ }^{4}$ acaba instaurando problemas de ineficiência e descontrole no manejo da informação. Ora, os economistas sempre defenderam com veemência que quanto melhor for a qualidade da informação, melhor tende a ser a tomada de decisão, o que, em regra, deveria aumentar o seu grau de eficiência (MAYER-SCHONBERGER, 2009 , p. 93). Essa constatação até pode ser verdadeira em geral e quando pensada a curto prazo. No entanto, o excesso na exposição ilimitada de dados sobre o seu próprio passado acaba, em contrapartida, expondo o indivíduo - e a sociedade como um todo - a consequências paralelas que podem ser negativas e indesejadas. Isso porque a memória digital perfeita - que obriga o sujeito a sempre lembrar de seu passado, numa espécie de imortalidade informacional (MAYER-SCHONBERGER, 2009, p. 97) - cria um dever de filtrar, selecionar, ordenar e interpretar um volume estrondoso de informação, com todos os custos e gastos de energia envolvidos nessa empreitada, consequências essas que a antiga 
tendência ao esquecimento gradual acabava evitando. Esse cenário de imortalidade informacional, segundo Mayer-schonberger (2009, p. 112), traz outras consequências que modificam não apenas o comportamento dos indivíduos, mas a forma de interação em sociedade. Isso ocorre na medida em que a irrestrita exposição pública - intencional ou não - de informações pessoais na rede mundial de computadores:

(i) provoca uma reordenação no balanço de poder entre os membros da sociedade ${ }^{5}$, em que o particular, que divulga publicamente seus atos, sua imagem e suas preferências, entrega a terceiros, ao menos em parte, o controle sobre as suas decisões, na medida em que estes passam a exercer influência sobre as suas escolhas futuras, mesmo que sem o seu consentimento explícito;

(ii) o risco de não ter controle sobre os dados pessoais que serão publicizados na Internet acaba criando, mesmo nos mais precavidos, um sentimento de autocensura no que se refere ao conteúdo a ser divulgado;

(iii) impede que o tempo exerça sua função natural de gradualmente apagar elementos do passado (MAYER-SCHONBERGER, 2009, p. 123), o que acaba dificultando a tomada racional de decisão por parte dos indivíduos, que se veem sobrecarregados com um volume de dados que necessitam processar, avaliar e ordenar para que alcancem uma conclusão sobre a melhor forma de proceder em determinado caso;

(iv) em um plano social, pode vir a reforçar o sentimento de rancor, na medida em que impede que os erros do passado - de menor relevância ou não mais importantes - sejam perdoados, e;

(v) em um plano individual, pode vir a desestimular aprendizagem e aprimoramentos pessoais, pois o sujeito que sabe que estará para sempre vinculado aos seus erros do passado poderá não se sentir inclinado a corrigir os seus defeitos nem evitar escolhas equivocadas (MAYERSCHONBERGE, 2009, p. 127).

Dessa forma, esse excesso na exposição do particular em relação aos seus atos pretéritos, perante os seus pares em sociedade, reflexamente provoca um aumento na propensão de se submeter o passado a um tribunal popular, avaliando-o com base nos critérios que prevalecem no presente (HOSKINS, 2014, p. 57). Aliás, nesse novo contexto, Baudrillard (1994) qualificou a sociedade contemporânea como altamente revisionista do 
passado, o que acaba criando ou ampliando atitudes de ressentimento em relação aos nossos antepassados. Por isso, segundo Gstrein (2016, p. 17), vivemos um fenômeno social caracterizado pela presença de um Observador Global que acompanha e controla cada um dos nossos passos diários. Com isso, a sociedade da hiperinformação acabou criando uma espécie de Digital Panopticon, em que, diferentemente do pensado por Jeremy Bentham (2001, p. 29), a prisão informacional que controla o comportamento é guardada não apenas por autoridades estatais, mas por todos os membros da sociedade (MAYER-SCHONBERGER, p. 11, e 110).

É precisamente dentro desse contexto histórico - marcado pela digitalização quase integral da realidade, e pelo surgimento da chamada memória perfeita e da eternidade informacional - que emerge a relevância de cultivarmos instrumentos jurídicos que adequadamente deem conta dos problemas sociais e dilemas éticos que surgem nesse cenário (MAYER-SCHONBERGER, 2009, p. 14). E, com grande probabilidade, o chamado direito ao esquecimento representa a ferramenta apta a resolver ao menos alguns desses conflitos.

Pois bem, feitos tais esclarecimentos contextuais e preliminares, cabe analisar se a expressão "direito ao esquecimento" se mostra efetivamente adequada e compatível com o conjunto de relações sociais que tal instituto jurídico visa a regular e proteger.

\section{PROBLEMAS NA NOMENCLATURA “DIREITO AO ESQUECIMENTO"}

\section{IMPORTÂNCIA E DIFICULDADES NO ATO DE DENOMINAR UM INSTITUTO JURÍDICO}

A adequada denominação de um instituto jurídico representa uma das mais relevantes (e talvez uma das mais complicadas) atividades teóricas que alguém dedicado ao estudo do Direito pode assumir. Isso porque a escolha da terminologia que possa ser considerada a mais correta ou a mais útil irá conduzir, em grande parte, o rumo das discussões jurídicas que envolverão tal conceito, delimitando, assim, o próprio 
escopo de análise dos elementos que estão em disputa e direcionando, por consequência, as diferentes propostas de solução dos conflitos que surgirão dentro do contexto em que tal novel expressão se mostre pertinente.

Um novo conceito jurídico não poderá ser tão simples e genérico a ponto de poder representar toda e qualquer dimensão da realidade (o que prejudica a própria função denotativa e identificativa que todo e qualquer conceito deve almejar), nem poderá ser tão complexo e sofisticado que apenas alguns poucos - normalmente os próprios proponentes da expressão - estarão capacitados a efetivamente compreender o seu quadrante correto de aplicação (prejudicando, assim, a dimensão de comunicabilidade e de inteligibilidade que conceitos necessitam projetar para que possam ter alguma utilidade prática).

Portanto, uma nomenclatura específica sendo proposta pelos operadores do direito deverá não apenas buscar a melhor representação da natureza das relações humanas particulares a serem afetadas pelo novo instituto jurídico, mas deverá também coordenar coerentemente os termos escolhidos com os bens jurídicos promovidos e tutelados pelo sistema jurídico em vigor, e que passarão a receber uma nova forma de regulação ou proteção. Com isso, um novo conceito jurídico deverá, simultaneamente, buscar uma correspondência mínima com a parcela da realidade prática que passará a ser por ele regulada, assim como deverá manifestar coerência e consistência com os enunciados do direito positivo vigente que, invariavelmente, devem ser considerados na construção da terminologia jurídica sendo inaugurada.

Por fim, um último fator - de peso secundário - deverá ser analisado e considerado quando da elaboração de um novo termo jurídico, o qual não diz respeito nem à dimensão ontológica das relações sociais a serem ordenadas, nem ao conteúdo das proposições que estão positivadas no sistema jurídico vigente, mas toca especificamente na forma como os integrantes das comunidades jurídicas convencionam e usam habitualmente determinado vocabulário. Nesse particular, mostra-se pertinente (mesmo que não possa ser determinante nem ser o critério final de justificação) avaliar o modo pelo qual acabam sendo convencionadas certas expressões jurídicas pela doutrina e pelos 
profissionais do direito, as quais podem ser de uso comum, amplamente consensualizado, mesmo que não denotem, com precisão, a realidade sendo captada, nem o conteúdo prático que pretendem regular. Isso significa dizer que, algumas vezes, determinados conceitos jurídicos podem gozar de ampla aceitabilidade, tanto pela academia quanto pelos operadores do direito, mesmo que os termos sendo utilizados possam conter expressões obscuras, imprecisas e lacunosas.

Desse modo, é importante deixar destacado que a análise crítica de terminologia fortemente consensualizada junto à comunidade jurídica se mostra sempre relevante, especialmente para verificação da sua adequação e coerência, mesmo que esse critério não possa ser visto como determinante, até porque, em termos científicos, o mero uso reiterado de um conjunto de palavras jamais será motivo suficiente para que esse seja aceito como o melhor conceito jurídico a ser utilizado.

De outro lado, não se pode também perder de vista que, em determinados casos, a convenção de uma nomenclatura específica se encontra tão arraigada no senso comum, é reproduzida de modo tão reiterado pela doutrina e é utilizada com tamanha frequência pelos tribunais, que a tentativa de sua substituição por outros termos - mesmo que sabidamente mais adequados e precisos - poderá ser inútil, excessiva e até arbitrária. Diante disso, é tarefa do teórico do direito saber - sem abdicar do seu espírito crítico - balancear a importância da tarefa de buscar o melhor conceito jurídico possível (em termos de sua veracidade, coerência e consistência), com o respeito e a aceitação de determinadas expressões que tenham sido consolidadas pelo uso acadêmico e prático, mesmo que não sejam idealmente as mais adequadas e precisas.

Pois bem, tais esclarecimentos são fundamentais para se bem compreender a relevância e utilidade no uso da expressão "direito ao esquecimento", de modo a permitir que, no item que segue, seja ela submetida a uma análise crítica da sua higidez e coerência, mesmo que não venha a ser possível, no atual cenário teórico e prático, a sua automática substituição por outro termo. 


\section{CRÍTICA À EXPRESSÃO “DIREITO AO ESQUECIMENTO”: POR UMA TERMINOLOGIA MAIS COERENTE E RAZOÁVEL}

Primeiramente, impõe-se destacar que, em uma perspectiva histórica, o termo direito ao esquecimento assume contornos bastante recentes ${ }^{6}$. Isso é importante para se colocar a questão no seu correto quadrante temporal, reconhecendo que a inovação terminológica sendo introduzida pela doutrina (tanto internacional, quanto pátria) ainda está em processo de maturação e aceitação.

Além disso, assim como ocorre em qualquer caso de inovação conceitual, impõe-se realizar uma explicitação clara dos fundamentos jurídicos que inspiraram o novo conceito sendo proposto, especialmente para diferenciá-lo daqueles institutos tradicionais e já consolidados, até porque, se esse novo conceito puder ser considerado indissociável ou sempre passível de confusão com os já fixados e estabelecidos na nossa cultura jurídica, o próprio intento de introduzir o novel instituto jurídico seria redundante e contraproducente (trazendo, aliás, para a prática jurídica, mais obscuridade e maior confusão). Aliás, como se diz, um conceito que serve para tudo e para qualquer coisa, em verdade não serve para nada. Portanto, é imperativo - em esforço classificatório e crítico dos conceitos jurídicos pertinentes - diferenciar o sentido próprio do direito ao esquecimento dos demais direitos que o inspiram ou fundamentam, como direito à privacidade, à personalidade, à intimidade, à honra, à imagem, etc ${ }^{7}$.

Antes de se adentrar na análise crítica e de mérito acerca da terminologia, cabe reconhecer que ela, mesmo que tenha sido introduzida apenas em período bastante recente, já se encontra relativamente bem consolidada junto à doutrina internacional, o que se comprova pela adoção quase uniforme, na maioria dos países que já enfrentaram questões dessa natureza, de expressões que representam traduções aproximadas dessa mesma expressão. Não é por outro motivo que encontramos na língua inglesa o right to be forgotten (FELLNER, 2014), em espanhol, o derecho al olvido (PENA, 2014), em francês, o droit à l'oubli (QUÉLIZ, 2016), em italiano, o diritto all'oblio (AMBROSOLI, 2017) e, em alemão, o Recht auf 
Vergessenwerden (GSTREIN, 2016; DIESTERHÖFT, 2014; STEHMEIER; SCHIMKE, 2014; SCHULZE, 2013).

Respeitando-se o antes destacado elemento de consensualização no uso dessa terminologia, constata-se que uma completa ruptura com a expressão "direito ao esquecimento" não seria salutar nem recomendável. Isso porque, tal atitude, ao se apartar do consenso estabelecido por grande parte da comunidade jurídica (nacional e internacional), estaria desprezando o fator de facilitação comunicativa que se faz presente quando se adota um conceito aceito pela maioria. Além disso, tal postura dificultaria, em parte, o diálogo com os interlocutores interessados em aprofundar o debate envolvendo esta nova gama de conflitos jurídicos que estão surgindo em nossa sociedade da hiperinformação. Em verdade, a substituição no uso de um conceito que já possui, em seu favor, o prestígio da consensualização deve ocorrer de modo gradual e orgânico junto à comunidade de operadores do direito, para que não haja ruptura drástica e perda na qualidade do discurso racional que deve sempre ser almejada. Exatamente por isso, neste artigo, não obstante a crítica que se fará em seguida, persistirá sendo utilizada, por razões pragmáticas, a consagrada expressão "direito ao esquecimento" (mas em destaque, precisamente para ilustrar o seu traço quase metafórico, bem como as dificuldades terminológicas que apresenta).

Antes de mais nada, impõe-se reconhecer que esta terminologia deixa muito a desejar, sendo marcada por enorme imprecisão e confusão conceitual (GSTREIN, 2016, p. 19). O termo "esquecimento", no caso, mostra-se equívoco por, ao menos, dois motivos: (a) ele não deixa claro exatamente qual a pretensão jurídica tutelada e (b) ele não denota com precisão a específica dimensão das relações humanas que serão reguladas por esse novo instituto jurídico.

Em nosso vernáculo, o substantivo masculino esquecimento corresponde ao ato, processo ou efeito de esquecer (HOUAISS, 2001, p. 1239), o que, por si só, já demonstra que o vocábulo direito ao esquecimento não é perfeitamente condizente com essa ideia, pois ele não pretende propriamente tutelar o modo pelo qual cada indivíduo irá desenvolver os seus processos internos que levam ao esquecimento, nem regular as consequências jurídicas de se esquecer algo sobre o 
seu passado. Obviamente, há certa distância entre a ideia geral de esquecimento - em seu sentido vernacular - e o termo em si, presente na locução jurídica objeto do presente estudo (GSTREIN, 2016, p. 18), sendo certo que, neste último caso, o uso dessa expressão tem a intenção de projetar, como já dito, um certo sentido metafórico.

Portanto, a construção de um conceito mais adequado, que mantenha proximidade com o termo comumente aceito, mas que melhor represente a real natureza das relações humanas que pretendem ser protegidas e reguladas, deverá ser suficiente para captar três elementos constitutivos desse novo direito fundamental, os quais já foram destacados no tópico anterior, quais sejam:

(i) as pretensões jurídicas aqui pertinentes tocam em questões envolvendo as consequências que são geradas em razão das grandes inovações tecnológicas do nosso século (e.g., as potentes redes de armazenamento e transmissão de dados e as ferramentas de consulta e pesquisa na Internet), as quais fazem surgir a antes denominada memória digital perfeita e a eternidade informacional;

(ii) a gradual diluição das fronteiras tradicionais da esfera pública e da esfera privada, o que é provocado pela nova tendência a uma cultura do exibicionismo social (i.e., a exposição exagerada de aspectos da vida particular em espaços públicos globalizados), reconfigurando as fronteiras da privacidade e intimidade de cada um, bem como o modo como delimitamos o exercício de outras liberdades, como a de informação, de imprensa e de livre manifestação de ideias ${ }^{8}$; e

(iii) a soma desses dois fatores cria uma série de novos conflitos, em razão dos riscos sociais e das dificuldades de convivência que surgem em um ambiente em que as informações verdadeiras sobre o passado de cada um podem ser sempre rememoradas no presente, de modo a forçar alguém a reviver lembranças traumáticas, revigorando as chagas do passado e impedindo a sua necessária cicatrização, o que acaba inviabilizando a estruturação saudável de um futuro ainda não escrito. 
Portanto, de modo sintético, pode-se concluir que a ideia central vinculada ao direito ao esquecimento está conectada, não com o ato, processo ou efeito de esquecer, mas sim com o fundamento de não obrigar ninguém a uma lembrança permanente do seu passado, em razão das novas tecnologias de processamento e de armazenamento de dados informatizados. Desse modo, se fosse para manter-se fiel à nomenclatura mais aceita, soaria mais razoável, ao invés de direito ao esquecimento, as expressões direito de não ser forçado a lembrar, direito de ser esquecido ${ }^{9}$ ou até mesmo Direito de silenciar eventos passados que não mais são pertinentes ao presente (PINO, 2000, p. 225-237).

No entanto, essa terminologia ainda manifesta alguma imprecisão e obscuridade, razão pela qual pode ela ser melhor especificada e esclarecida. Nesse particular, cabe destacar que a doutrina alemã - com seu típico rigor analítico - é possivelmente a que, com maior clareza e sistematicidade, propôs conceitos que ilustram o sentido próprio do chamado direito ao esquecimento.

Com efeito, merece destaque, primeiramente, a detalhada proposta conceitual desenvolvida por Gstrein, o qual, não abandonando o tradicional termo "direito de ser esquecido" (Recht auf Vergessenwerden - RVw), veio a ampliar o escopo de especificação conceitual relacionados a esse direito e aos conflitos por ele regulados, introduzindo os seguintes conceitos adicionais: o direito à não-indexação (Recht aufNicht-Indexierung - RNI), a cascata da decomposição informacional (Die Kaskade des Informationellen Verfalls - KdiV) e o direito à autodeterminação informativa (Recht auf informationelle Selbstbestimmung). Tais expressões de nenhum modo podem ser vistas como sinônimas à nomenclatura usual, assim como não estão todas elas em uma posição de equidistância em relação a esse novo direito. Em verdade, representam ideias correlatas que ou resgatam elementos do seu fundamento ou especificam pretensões jurídicas de menor extensão que com ele mantêm conexão. Assim, vejamos.

Em primeiro lugar, o denominado direito à não-indexação (Recht auf Nicht-Indexierung - RNI) alcançaria, em tese, uma fatia menor do espectro regulado pelo direito ao esquecimento (GSTREIN, 2016, p. 21), na medida em que trataria apenas das situações em que a preservação do passado informacional de alguém se daria por meio da imposição de mecanismos 
de bloqueio nas ferramentas de pesquisa disponíveis na Internet (e.g., Google, Yahoo, Bing, etc...), as quais estariam obrigadas a desindexar dos seus bancos de dados determinado conjunto de informações (restringindo resultados quando do preenchimento de palavras-chave em uma consulta realizada). Nesses casos, portanto, não se determina a exclusão ou o apagamento das informações arquivadas, mas apenas se impede que o conteúdo, que se deseja tornar indisponível, seja acessado e resgatado dos seus sistemas informatizados (GSTREIN, 2016, p. 21). Já o direito ao esquecimento, compreendido em sentido amplo, poderá tanto envolver o controle informativo de outras mídias de transmissão e armazenamento de dados, além dos meios digitais (como, por exemplo, mídias impressa, televisa e de rádio), como, também, poderá exigir outros instrumentos jurídicos de proteção do indivíduo em relação aos seus dados pessoais do passado, os quais sofrerão restrições em seu acesso por não manifestarem mais nenhuma pertinência ou atualidade.

Em segundo lugar, o direito ao esquecimento se conecta com uma ideia conexa que Gstrein (2016 p. 24 e 256) caracteriza como Die Kaskade des Informationellen Verfalls - KdiV, a qual pode ser compreendida pela noção de que todas as informações hoje armazenadas estão submetidas a um processo gradual de decadência progressiva, no que se refere à sua relevância informacional. Mesmo que ele não forneça um critério objetivo para seu controle, nem uma metodologia para sua aplicação, tal interessante e criativa expressão é relevante para se avaliar, diante do caso concreto, a pertinência e atualidade do conteúdo informativo que determinada pessoa poderá estar buscando excluir ou impedir-lhe o acesso. Por isso, a expressão aqui proposta - cascata da decomposição informacional - mantém estreita relação de simetria com o critério aplicativo proposto em artigo já publicado por este autor, no qual se defendeu a necessidade de se observar o esgotamento da relevância informativa (FERREIRA NETO, 2017).

Em terceiro lugar, Gstrein (2016, p. 256) traz à tona a noção de um direito à autodeterminação informativa (Recht auf informationelle Selbstbestimmung), o qual reflete, com precisão, o fundamento e a essência da proteção individual que, no fundo, pretende-se resguardar quando se invoca o direito ao esquecimento. Isso porque, conforme se 
verá no tópico que segue, o direito ao esquecimento mantém próxima relação com a pretensão individual de controlar o manuseio e a transmissão de informações pessoais passadas e que sejam, ainda hoje, acessíveis pelos demais membros da sociedade, buscando, com isso, garantir que cada indivíduo possa preservar elementos importantes de sua identidade contra os efeitos danosos de fatos pretéritos, permitindo que ele próprio direcione a construção da sua personalidade futura. Com efeito, a necessidade de se resguardar, nesses casos, uma autodeterminação informativa, transmite com clareza a noção de que o direito ao esquecimento se relaciona mais diretamente com o direito à identidade do que com o direito à privacidade, mesmo que com esse mantenha uma conexão relevante (ANDRADE, 2014, p. 66).

Deste modo, concluindo o presente tópico, cabe mencionar a sugestão terminológica apresentada por Diesterhöft (2014), que captura com perfeição, em uma locução, os três elementos acima destacados e que, por isso, representa, possivelmente, a mais razoável expressão a ser utilizada em substituição à presente no paradigma atual. Propõe ele o uso da expressão "direito a um recomeço nas mídias sociais" (Das Recht auf Medialen Neubeginn), a qual capta adequadamente tanto o fundamento dessa pretensão jurídica, qual seja, o desejo de se garantir ao particular o seu direito a uma autodeterminação informativa, como também o conteúdo da tutela pretendida, que envolve a possibilidade de reconfigurar e direcionar a construção da identidade pessoal e da imagem social do indivíduo, tendo em vista o conteúdo dos dados pessoais que estejam armazenados em sistemas digitais de informação, os quais, com o passar do tempo, devem ser atualizados, reconfigurados, bloqueados ou até, em alguns casos, apagados.

Com efeito, mesmo que a nomenclatura atual não possa ser sumariamente abandonada, tendo em vista o seu alto grau de consolidação junto à comunidade jurídica contemporânea, a expressão "direito a um recomeço nas mídias sociais" surge como uma alternativa adequada para a sua substituição no futuro, caso se entenda necessária a adoção de uma expressão que represente, com maior precisão e fidelidade, a realidade jurídica que esse novo instituto pretende regular. 


\section{FUNDAMENTAÇÃO JURÍDICA DO DIREITO AO "ESQUECIMENTO": ENTRE A PROTEÇÃO À PRIVACIDADE E O LIVRE DESENVOLVIMENTO DA IDENTIDADE PESSOAL}

Neste último tópico, pretende-se averiguar qual é a melhor forma de se legitimar e justificar, perante o ordenamento jurídico, o direito ao esquecimento, de modo a verificar se as pretensões jurídicas que, em regra, visam a ser resguardada, quando da invocação desse conceito, tocam prioritariamente em questões envolvendo a proteção à privacidade de um indivíduo ou em questões envolvendo o livre desenvolvimento público e externo de aspectos da sua personalidade e da sua identidade pessoal.

Em primeiro lugar, impõe-se reconhecer que o direito ao esquecimento não pode ser compreendido como uma nova pretensão jurídica que se encontra isolada e incomunicável diante do grande universo dos direitos fundamentais. Conforme já destacado, esse novel instituto jurídico somente pode ser adequadamente compreendido quando se levam em consideração as novas proteções individuais que começam a se articular dentro do nosso atual contexto hipercomunicativo, em que os avanços tecnológicos criam inéditos conflitos envolvendo o manejo, a transmissão e a guarda de dados pessoais por parte de órgãos governamentais e de entidades privadas, o que acaba impondo uma reconfiguração nos espaços público e privado. E é precisamente dentro desse novo cenário que surgem dois conjuntos de direitos e liberdades que se colocam em contraposição, quase como se fixassem polos antagônicos de interesses jurídicos - em constante tensão - que necessitam ser equacionados e balanceados diante do caso concreto, sendo o direito ao esquecimento um dos instrumentos jurídicos (mas não o único) que pretende especificamente assumir essa tarefa.

E dentro dessa intersecção de pretensões jurídicas, temos, de um lado, a gama de proteções que afetam os interesses dos indivíduos prejudicados pela exposição de suas informações pessoais (tocando em questões envolvendo a dignidade humana, bem como os direitos de personalidade, privacidade, intimidade etc.), enquanto que, de outro, 
temos a necessidade de serem respeitados os interesses do restante da coletividade, especialmente no que se refere aos potenciais benefícios sociais que serão promovidos ao se permitir o livre acesso e a ampla divulgação dessa mesma informação (envolvendo aqui as liberdades de imprensa, manifestação de pensamento, de expressão artística, intelectual, científica etc.). 0 direito ao esquecimento, portanto, representa uma forma de se resolvem alguns dos conflitos que surgem dentro do contexto em que tais esferas de direitos e liberdades se encontram tensionadas. No entanto, por óbvio, não são todas as disputas envolvendo interesses privados de não exposição pública contrapostos a interesses coletivos de divulgar e acessar informações sobre terceiros que serão resolvidas pela utilização do direito ao esquecimento. Por essa razão, para melhor delimitar esse campo de aplicação, impõe-se verificar e justificar qual o fundamento jurídico-positivo do direito ao esquecimento, para, em seguida, relacionálo com outros direitos fundamentais que atuam nesse mesmo campo de conflitos (e.g., o direito de ser informado e o direito de não ser informado) - (CHADWICK; LEVITT; SCHICKLE, 2014). Assim, vejamos.

Primeiramente, cabe ressaltar que o direito ao esquecimento não deve ser compreendido como sendo uma simples especificação do direito à privacidade, nem uma derivação do direito de proteção de dados, mesmo que com esses mantenha uma clara relação. Em verdade, conforme já adiantado no tópico anterior, este está mais atrelado a uma pretensão de autodeterminação do indivíduo relativamente às informações - sejam aquelas armazenadas em meio digital, sejam as conservadas por meio de outro suporte físico ${ }^{10}$ - sobre sua esfera pessoal que estejam colocadas à disposição de todos por tempo indeterminado, visando, com isso, não apenas a proteger a sua privacidade, mas especialmente permitir que ele possa direcionar ou reconstruir a sua imagem, tal como apresentada publicamente perante os demais membros da sociedade que terão acesso a tais dados pessoais.

Portanto, como se pretende agora demonstrar, com maior precisão, as raízes do direito ao esquecimento estão melhor fundadas em direitos de personalidade, mais especificamente, no direito à identidade e no referido direito à autodeterminação informacional (Recht auf informationelle Selbstbestimmung), do que no direito à privacidade e 
seus correlatos (intimidade, honra, sigilo de correspondência e dados etc.). Isso porque o direito ao esquecimento não busca primariamente impedir que os demais membros da sociedade venham a alcançar uma esfera íntima, privada, afastada do público, a qual em nenhuma hipótese poderia ser legitimamente penetrada pela coletividade. Ora, nos casos que tipicamente envolvem o direito ao esquecimento, as informações ou dados pessoais que se desejam retificar, obstaculizar o acesso, ou até apagar, sempre estiveram disponíveis à coletividade, as quais, porém, passarão, a partir de determinado momento, não serem mais relevantes, razão pela qual não mais poderão ser oferecidas ao escrutínio público. Isso demonstra que o direito ao esquecimento apenas reflexamente visa a resguardar questões de proteção à privacidade.

Para ilustrar tal ponto, pode-se citar o argumento apresentado por Korenhof e Koops (2014, p. 102-126), os quais sustentam que o direito ao esquecimento pode alcançar questões envolvendo nova identidade de gênero e as consequentes retificações em dados cadastrais, disputas judiciais essas que não tocam precisamente no tema do direito à privacidade, mas sim em direitos de personalidade. Nesses casos, não se pretende evitar que terceiros tenham acesso a informações pessoais do indivíduo que pretende ter reconhecida nova identidade de gênero, mas se discute se a imagem social do indivíduo poderá ou não ser reconfigurada de modo a representar, para si e para o restante da comunidade, gênero distinto daquele constante originariamente dos registros públicos, o que poderá inclusive impor - caso procedente a pretensão - a retificação e exclusão do conjunto de informações que o apresentavam como aquela pessoa com a qual esse indivíduo não mais deseja se identificar. Cabe esclarecer que não se quer aqui defender que tais pretensões sejam necessariamente procedentes em todos os casos, mas apenas afirmar que o instituto do direito ao esquecimento poderá adequadamente ser utilizado como instrumento de argumentação, de modo a pautar tais disputas jurídicas como representando questões envolvendo direitos de desenvolvimento da identidade pessoal.

Assim, partindo-se dessas premissas e adotando-se a proposta classificatória desenvolvida por Andrade (2014, p. 66), cabe explicitar como se pode fundamentar o "direito ao esquecimento" a partir das 
noções de autodeterminação e reconstrução da identidade pessoal por meio de atualizações e retificações do passado informacional do indivíduo.

Para tanto, mostra-se necessário, primeiramente, separar a dimensão procedimental/formal e a dimensão substantiva/material dos direitos pertinentes à proteção dos dados digitais relacionados à esfera privada dos particulares. Com efeito, de um lado, encontra-se o direito "procedimental" à proteção de dados pessoais, o qual dispõe sobre os meios (i.e., as técnicas e procedimentos) que deverão ser observados (e garantidos em caso de violação) nos atos de manutenção, transmissão, alteração e, inclusive, remoção das informações e dados pessoais.

Essa dimensão instrumental do direito sendo aqui analisado, portanto, dedica-se a regular os mecanismos de armazenagem que terão de ser respeitados tanto por agentes governamentais como por entidades privadas que se dedicam a esse tipo de atividade econômica, envolvendo, por exemplo, a fixação de prazos de validade na preservação de dados informatizados, bem como os critérios e condições para a supressão do consentimento referente ao registro dos mesmos dados pessoais.

Ao lado dessas preocupações jurídicas de ordem formal, encontramse interconectados tanto o direito material à privacidade, quanto o direto material à identidade, os quais não são em si antagônicos, mas assumem uma posição de complementariedade, na medida em que ambos são derivados do direito de personalidade pertencente a cada indivíduo, buscando o seu fundamento tanto na dignidade da pessoa humana quanto no direito fundamental à autodeterminação (ANDRADE, 2014, p. 67).

Conforme antes referido, mesmo que mantenham próxima relação, privacidade e identidade não correspondem a pretensões jurídicas idênticas. Isso porque o direito à privacidade visa a proteger que determinados elementos da vida interna de um indivíduo sejam preservados e afastados do contato de terceiros, de modo a fixar limites e criar obstáculos que impeçam que determinadas facetas da sua esfera privada sejam reproduzidas - sem sua autorização - na esfera pública (ANDRADE, 2014, p. 68). Já o direito à identidade toca na pretensão de o indivíduo se apresentar e ser representado publicamente, mas sempre e exclusivamente de forma verdadeira e fiel à realidade, ou ao contexto 
em que esse se encontre atualmente inserido. Isso significa dizer que cada particular possui o direito de se ver reconhecido socialmente como sendo não apenas único, mas também diferente dos demais, o que lhe garante o direito de possuir um nome, uma aparência exclusiva, uma voz individual e principalmente uma narrativa pessoal. Além disso, no contexto contemporâneo da hiperinformação, o direito à identidade passa a abarcar a pretensão de moldar e de reconstituir a própria imagem social, tendo em vista as mudanças que são impostas na composição do indivíduo em razão do transcurso do tempo, o que permite que venha a se falar em um direito de ser diferente de si mesmo em relação ao passado (ANDRADE, 2014, p. 67). Por isso, o direito à identidade busca promover, em certo sentido, um objetivo quase oposto ao do direito à privacidade, na medida em que este visa a impedir que terceiros acessem informações sobre uma dimensão íntima do indivíduo, a qual se quer deixar fora do alcance público, enquanto que aquele deseja precisamente seja resguardada a exposição no espaço público, mas apenas daquela representação que fielmente captar a autoimagem indivíduo, de modo a garantir seja ele reconhecido e aceito pelos demais de acordo com a sua individualidade. E é precisamente dentro desse escopo de preservação da identidade manifestada no presente relativamente aos fatos ocorridos no passado que se pode estruturar o conteúdo essencial do direito ao esquecimento.

Além disso, com base em tais diferenças substanciais, podese dizer que o direito à privacidade assume traços (a) subjetivos, (b) primordialmente negativos e (c) de preservação, ao passo que o direito à identidade manifesta uma dimensão (a) intersubjetiva, (b) primordialmente positiva e (c) de construção ou reconstrução de significados.

Isso significa dizer, primeiramente, que a privacidade toca em fatos ou traços pertinentes exclusivamente à vida interna do particular, os quais não deveriam, por qualquer razão plausível, ser transmitidos a terceiros em um ambiente público, ao passo que a identidade pressupõe um vínculo de reconhecimento perante terceiros, o que levará à análise de como as informações pessoais - já disponíveis na esfera pública - são 
reproduzidas, acessadas ou mantidas, o que exige avaliar como tais dados são intersubjetivamente percebidos pelos demais membros da sociedade.

Em segundo lugar, a privacidade possui uma dimensão prioritariamente (mas não exclusivamente) negativa, pois assume uma função prioritariamente bloqueadora, visando a obstaculizar o acesso e a transmissão das informações que moldam a esfera íntima de cada particular. Já a identidade assume uma dimensão prioritariamente (mas não exclusivamente) positiva, pois envolve um modo de o indivíduo se apresentar ou ser representado no seu meio social, permitindo assim que tal direito seja afirmativamente configurado ou reconfigurado pelo seu detentor, de modo a permitir que ele participe ativamente na especificação do "como", do "quando" e do "para quem" as suas informações pessoais serão transmitidas ou reproduzidas.

Por fim, a privacidade manifesta uma feição preservativa, na medida em que projeta a intenção de respeitar e resguardar determinados aspectos internos, pessoais ou íntimos da vida, preservando-os da exposição não desejada e do escrutínio público. Por outro lado, a identidade possui uma dimensão construtiva (ou reconstrutiva), pois funciona como um instrumento de reconfiguração da imagem social que cada indivíduo pretende seja projetada em sociedade, de modo a permitir que esse venha a controlar a forma como os seus dados pessoais serão utilizados na sua representação pública e recebidos pelos demais membros da sociedade.

Cabe ressaltar que tais considerações não podem ser compreendidas como contendo a configuração completa do conteúdo jurídico do direito ao esquecimento, mas ilustram, apenas, em termos didáticos, uma forma plausível de se justificar a invocação desse novo direito fundamental diante de um caso concreto, o que poderá ser útil na estruturação e no controle dos argumentos jurídicos a serem articulados ou contraditados nessas situações. Para se visualizar com maior clareza as conclusões aqui alcançadas, pertinente a seguinte tabela ilustrativa: 


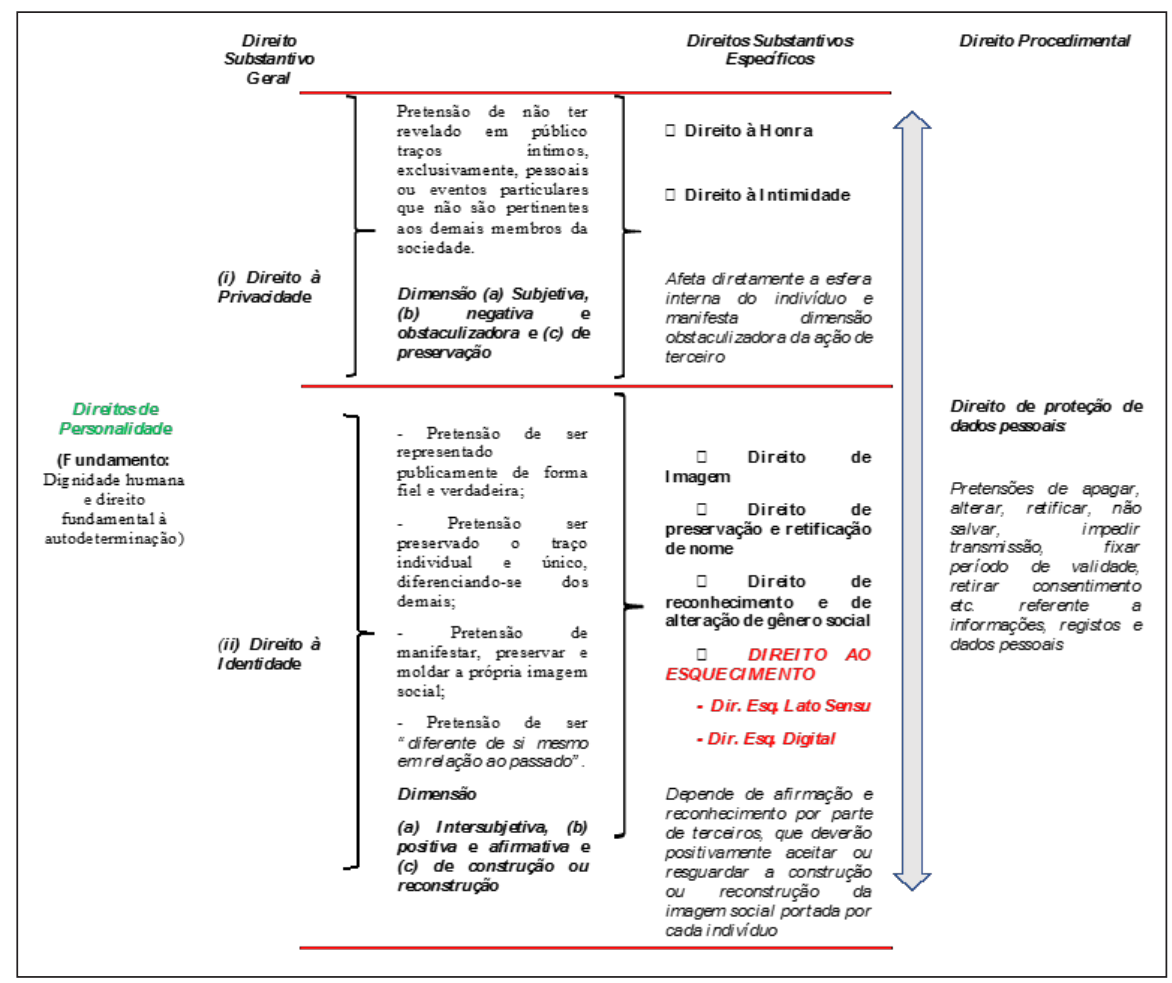

Fonte: Elaborada pelo autor.

\section{CONCLUSÃO}

O objetivo deste artigo foi o de avaliar de modo crítico o conceito forjado, pela doutrina e pela jurisprudência do novo instituto jurídico chamado de "direito ao esquecimento". Demonstrou-se que tal expressão, em verdade, representa alcunha que não bem captura os elementos jurídicos essenciais que efetivamente visam a ser protegidos e resguardados por meio desse novo direito fundamental. Por essa razão, uma nova terminologia veio a ser sugerida como mais coerente e adequada, não obstante a força do termo hoje consensualizado. 0 segundo objetivo deste texto foi o de resgatar o fundamento jurídico prioritário do "direito ao esquecimento", tendo se demonstrado que, não obstante mantenha relação paralela com a proteção à privacidade do indivíduo, tal novel pretensão jurídica possui uma relação direta e 
mais demarcada com o resguardo de direitos de personalidade, mais especificamente a autodeterminação da identidade informacional do particular. Portanto, sinteticamente, as seguintes conclusões foram alcançadas no presente estudo:

(i) A forma como nos relacionamos com a nossa memória foi, a contar deste século, completamente modificada, seja no que tange ao volume do conteúdo informacional preservado, seja no que se refere à segurança e persistência com que esse pode ser armazenado.

(ii) Isso, em grande parte, deve-seà configuração e popularização da chamada "memória digital", a qual se implementou graças a inovações tecnológicas introduzidas por meio da rede mundial de computadores, modificando, assim, a forma como manuseamos, transmitimos e armazenamos nossas informações pessoais.

(iii) Nesse novo contexto hipercomunicativo, o lembrar passa a ser a regra e a possibilidade de esquecimento - com o benéfico efeito de superar o passado, perdoar erros cometidos e permitir o aprimoramento pessoal - passa a ser exceção, submetendo os indivíduos ao risco de ficarem aprisionados em uma memória perfeita que não permite que nada seja obliterado, criando-se, assim, o chamado efeito eternidade da informação.

(iv) Assim, a Internet veio a provocar não apenas mudanças tecnológicas, mas também alterações culturais na forma como interagimos e como valoramos a nossa capacidade de memória - e quanto maior a interação social na troca de dados, maior a potencialidade para conflitos que necessitarão ser regulados e solvidos pelo direito.

(v) Diante desses desafios e paradoxos, passa-se a estruturar um novo direito fundamental, denominado "direito ao esquecimento", o qual é projetado com o propósito de regular e proteger precisamente as relações sociais surgidas dentro do contexto de ampla troca de informações e de armazenamento quase irrestrito de dados pessoais. 
(vi) Os avanços tecnológicos gerados pela memória perfeita acabam criando uma contradição, pois, de um lado, passamos a ter um contato imediato e perene com o nosso passado, criando-se a sensação de autocontrole sobre nossas memórias, mas, de outro, acabamos nos tornando vulneráveis ao escrutínio coletivo, na medida em que somos reféns de uma memória sempre acessível e resgatável.

(vii) A esse fenômeno se dá o nome de emergência de fatos passados, segundo o qual, diante do volume incontrolável de registros digitais de todos os aspectos de nossa vida diária, determinado evento que afetou a vida de alguém pode vir à tona repentinamente, fazendo emergir mais uma vez o passado no presente.

(viii) Além disso, a sociedade da hiperinformação acabou criando uma espécie de Digital Panopticon, em que a prisão informacional que controla nosso comportamento é guardada não apenas por autoridades estatais, mas por todos os membros da sociedade.

(ix) Com isso, os indivíduos aprisionados pela memória digital perfeita ficam impedidos de se beneficiar dos efeitos corrosivos do tempo, o qual deve exercer a sua função natural de gradualmente destronar as ocorrências pretéritas e depreciar o valor original de eventos do passado, o que, em regra, sempre teve uma importante função estabilizadora, ao garantir aos indivíduos segurança e certeza de que o presente iria, gradualmente, se sobrepondo ao passado.

(x) A nomenclatura "direito ao esquecimento", mesmo que consagrada pela doutrina e pela jurisprudência, tanto no exterior, quanto no Brasil, não se mostra perfeitamente compatível com as relações sociais que ela pretende regular, nem com os bens jurídicos que ela visa a tutelar. Por essa razão, mesmo que se possa respeitar o fator de consensualização presente no uso dessa terminologia, não se pode deixar de submetê-la à crítica. 
(xi) O termo "esquecimento" é equívoco por, ao menos, dois motivos: (a) não deixa claro ,exatamente, qual a pretensão jurídica tutelada e (b) não denota com precisão a específica dimensão das relações humanas que serão reguladas por esse novo instituto jurídico.

(xii) O substantivo masculino "esquecimento" corresponde ao ato, processo ou efeito de esquecer, o que demonstra que o termo utilizado para nomear o instituto em tela não é condizente com essa ideia, pois não pretende tutelar o modo pelo qual cada indivíduo irá desenvolver os seus processos internos que levam ao esquecimento nem regular as consequências jurídicas de se esquecer algo sobre o seu passado.

(xiii) Em verdade, o direito ao esquecimento se vincula à ideia de não obrigar ninguém a uma lembrança permanente do seu passado, sendo mais coerentes, se se preferir dar prevalência a expressões metafóricas, o direito de não ser forçado a lembrar, o direito de ser esquecido ou, até mesmo, o direito de silenciar eventos passados que não mais são pertinentes ao presente.

(xiv) Por fim, quanto à mais adequada fundamentação jurídica do direito ao esquecimento, pretendeu-se neste artigo sustentar que ele não deve ser compreendido como simples especificação do direito à privacidade nem derivação do direito de proteção de dados.

(xv) Na verdade, sustentou-se que ele está mais atrelado a uma pretensão de autodeterminação do indivíduo relativamente às informações digitais sobre sua esfera pessoal que estejam colocadas à disposição de todos por tempo indeterminado, visando, com isso, não apenas proteger a sua privacidade, mas especialmente permitir que ele possa direcionar ou reconstruir a sua imagem digital perante os outros que terão acesso a tais dados pessoais.

(xvi) Portanto, argumentou-se que as raízes do direito ao esquecimento estão melhor fundadas no direito à identidade 


e no direito à autodeterminação informacional (Recht auf
informationelle Selbstbestimmung), na medida em que não
busca primariamente impedir que os demais membros da
sociedade venham a alcançar uma esfera íntima, privada,
afastada do público, a qual em nenhuma hipótese poderia
ser legitimamente penetrada pela coletividade, mas sim
garantir que o indivíduo possa exercer controle sobre as
construção e reconstrução da sua imagem social, tendo
em vista as informações do seu passado, as quais poderão
ser consideradas irrelevantes ou descontextualizadas no
presente e, inclusive, para o futuro.

\section{NOTAS}

1 Aliás, em Fedro, Platão já anunciava o risco que se assume ao se deixar por escrito determinada tese ou opinião, a qual, uma vez reduzida a termo, distancia-se parcialmente do seu autor, passando a vagar solta pelas infinitas possibilidades interpretativas dos diferentes membros da sociedade e, inclusive, das futuras gerações, de modo que a ideia original poderá sofrer todo tipo de distorção, gerando, com isso, falhas comunicativas e até prejuízos àquele que inicialmente a produziu. ("When it has once been written down, every discourse roams about everywhere, reaching indiscriminately those with understanding no less than those who have no business with it, and it doesn't know to whom it should speak and to whom it should not. And when it is faulted and attacked unfairly, it always needs its father's support; alone, it can neither defend itself nor come to its own support." - PLATÃO. Fedro, in Plato - Complete Works. Estados Unidos da América: Hackett, 275, d-e, p. 552).

20 processo analógico exige uma intervenção física na mídia de armazenamento (e.g., magnetização da superfície de um disco ou fita), o que acaba criando ruídos na reprodução e a depreciação gradual dos dados armazenados a cada cópia produzida. 0 mundo analógico, portanto, é perfeitamente compatível com a exigência humana de parcialmente esquecer o seu passado. (MAYER-SCHONBERGER, 2009, p. 52-62).

3 MAYER-SCHONBERGER (2009, p. 68) exemplifica tal fenômeno (até certo ponto contra-intuitivo) citando a prática costumeira de hoje em dia baixarmos para o computador a integralidade das fotos registradas em uma máquina fotográfica digital - mesmo que não desejemos efetivamente guardarmos todas -, na medida em que a análise individualizada de cada foto irá consumir muito mais tempo do que o simples ato de armazenar todas.

4 A referência à perda da nossa capacidade de esquecimento não pretende transmitir a ideia de que se está diante de uma incapacidade biológica de esquecer, mas apenas - em sentido metafórico - de que os indivíduos, dentro de uma matriz informacional hiperconectada, deparamse com um enorme empecilho para conseguir deixar o passado no passado, em razão do constante risco de lembrança pela Internet, no presente e no futuro, de eventos pretéritos. Aliás, nesse sentido, mostra-se bastante ilustrativa a expressão alemã - também metafórica - utilizada por Diesterhöft (2014, p. 23-54) de uma incapacidade da Internet de esquecer (Die "Unfähigkeit des Internets zu vergessen").

5 Segundo Gstrein (2016, p. 20), há uma conexão entre poder e tempo no direito ao esquecimento, na medida em que, como sabemos, conhecimento é poder. 
6 Não há consenso sobre o primeiro caso concreto em que o direito ao esquecimento tenha sido expressamente pautado como o elemento central de uma discussão jurídica (sobre o ponto vide Carello, 2017). De qualquer modo, mesmo que inúmeros casos judiciais tenham servido de inspiração para a estruturação desse novo direito, não há dúvida que o seu efetivo surgimento, nos contornos aqui propostos, deu-se há pouco mais de uma década.

7 Tal esforço diferenciador e classificatório será promovido no item 4 deste artigo.

8 Tal ponto é melhor explorado em trabalho anterior deste autor (FERREIRA NETO, 2017).

9 Essa expressão se compatibiliza melhor com o termo em alemão Recht auf Vergessenwerden.

10 Com base nessa diferenciação quanto ao tipo de mídia em que se encontra a informação pessoal a ser regulada e controlada pelo direito ao "esquecimento", torna-se possível separar tal categoria jurídica em "Direito ao Esquecimento Lato Sensu" e "Direito ao Esquecimento Digital" (ou Stricto Sensu).

\section{REFERÊNCIAS}

AMBROSOLI, Umberto; SIDERI, Massimo. Diritto all'oblio, dovere della memoria. L'etica nella società interconnessa. Itália: Bompiani, 2017.

BAUDRILLARD, Jean. The Illusion of the End. Estados Unidos da América: Polity Press, 1994.

BENTHAM, Jeremy. The Panopticon writings. Reino Unido: Verso, 2ª edição, 2001.

CARELLO, Clarissa Pereira. Direito ao Esquecimento: Parâmetros jurisprudenciais. Curitiba: Prismas, 2017.

CARNEROLI, Sandrine. Le droit à l'oubli: Du devoir de mémoire au droit à l’oubli. França: Larcier, 2016.

CHADWICK, Ruth; LEVITT, Mairi; SCHICKLE, Darren (editores). The Right to Know and the Right not to Know. Estados Unidos da América: Cambridge University Press, 2ª edição, 2014.

DIESTERHÖFT, Martin. Das Recht auf Medialen Neubeginn. Die “Unfähigkeit des Internets zu Vergessen" als Herausforderung für das allgemeine Persönlichkeitsrecht. Berlin: Duncker \& Humblot, 2014.

FELLNER, Robert. The Right to Be Forgotten in the European Human

Rights Regime. Alemanha: Grinn, 2014. 
FERREIRA NETO, Arthur Maria. Direito ao Esquecimento na Alemanha e no Brasil. In: MARQUES, Claudia Lima; BENICKE, Christoph; JAEGER JUNIOR, Augusto. (Org.). Diálogo entre o Direito Brasileiro e o Direito Alemão: Fundamentos, Métodos e Desafios de Ensino, Pesquisa e Extensão em Tempos de Cooperação Internacional. Porto Alegre: RJR, 2016, v. II, p. 278323.

GHEZZI, Alessia. The Ethics of Memory in a Digital Age - Interrogating the right to be forgotten. Reino Unido: Palgrave MacMillan, 2014.

GSTREIN, Oskar Josef. Das Recht auf Vergessenwerden als Menschenrecht - Hat Menschenwürde im Informationszeitalter Zukunft? Alemanha: Nomos, 2016.

HOUAISS, Antônio; VILLAR, Mauro de Salles. Dicionário Houaiss. São Paulo: Editora objetivo, 2001.

MALDONADO, Viviane Nóbrega. Direito ao Esquecimento. São Paulo: Novo Século, 2017.

MAYER-SCHONBERGER, Viktor. Delete: The Virtue of Forgetting in the Digital Age. Estados Unidos da América: Princeton University Press, 2009.

PLATÃO. Fedro, in Plato - Complete Works. Estados Unidos da América: Hackett, 1997.

PENA, Alejandro Touriño. El derecho al olvido en Internet. Espanha: Los Libros de la Catarata, 2014.

PINO, G. The Right to Personal Identity in Italian Private Law:

Constitutional Interpretation and Judge-made Rights. In HOECKE, Van M. e OST, François (ed.). The Harmonization of Private Law in Europe. Reino Unido: Hart Publishing, 2000.

QUÉLIZ, Anthony Abud. Le droit à l'oubli numérique en France et aux États-Unis. França: Univ. Européenne, 2016.

SCHULZE, Sebastian. Das Recht auf Vergessenwerden - Essentielles Grundrecht im Netz? Alemanha: Grin, 2013. 
STEHMEIER, Marinus; SCHIMKE, Anna. Internet-Suchmaschinen und Datenschutz - Zugleich eine Besprechung von EUGH C-131/12 Google Spain und Google. Alemanha: Archive fur Urheber- und Medienrecht, Stampfli, 2014.

WALKER, Robert K. The Right to be forgotten. Estados Unidos da América: Hastings Law Journal 2012.

WAREN, Samuel; BRANDEIS, Louis. The Right to Privacy. Estados Unidos da América: Harvard Law Review, Vol. IV, No. 5, 1890.

WEISMANTEL, Jan. Das »Recht auf Vergessenwerden« im Internet nach dem »Google-Urteil« des EuGH.: Begleitung eines offenen Prozesses. Alemanha: Duncker \& Humblot, 2017.

WHITMAN, James Q. The Two Western Cultures of Privacy: Dignity Versus Liberty. Estados Unidos da América, Yale Law Journal, vol. 113, 2004.

Recebido em: 16-11-2018

Aprovado em: 18-12-2018

\section{Arthur Maria Ferreira Neto}

Pontifícia Universidade Católica do Rio Grande do Sul

Mestre e doutor em Direito Tributário pela Universidade Federal do Rio Grande do Sul (2005 e 2015) e Mestre e Doutor em Filosofia pela Pontifícia Universidade Católica do Rio Grande do Sul (2008 e 2013), possuindo ainda Especialização em Direito Tributário pelo IBET (2002) e graduação em Ciências Jurídicas e Sociais pela Faculdade de Direito da UFRGS. 